\title{
Platelet adherence to cancer cells promotes escape from innate immune surveillance in cancer metastasis
}

\author{
MITSUYOSHI OKAZAKI, TAKAHISA YAMAGUCHI, HIDEHIRO TAJIMA, SACHIO FUSHIDA and TETSUO OHTA \\ Department of Gastroenterological Surgery, Division of Cancer Medicine, \\ Graduate School of Medical Science, Kanazawa University, Kanazawa, Ishikawa 920-8641, Japan
}

Received February 15, 2020; Accepted July 7, 2020

DOI: 10.3892/ijo.2020.5102

\begin{abstract}
The impacts of post-operative abdominal infectious complications increase hematogenous distant metastasis and result in poor long-term survival after curative resection. Even if curative resection can be performed, the presence of circulating tumor cells is affected. The liver, the most common site of metastases, is an important organ in innate immune surveillance. However, the molecular mechanisms of distant hematogenous metastasis are not yet fully known. Platelets are crucial components in the tumor microenvironment that function to promote tumor progression and metastasis. The purpose of this study was to identify the effect of platelets on escape from innate immune surveillance in post-operative abdominal infectious complications. Platelet adherence was assessed by co-culturing human pancreatic cancer cells including transforming growth factor (TGF- $\beta$ )-treated BxPC-3. CD44 isoform, transcription factors and epithelial-mesenchymal transition markers were examined using western blotting. We also assessed whether cancer cells surrounded by activated platelets could escape from innate immune surveillance, using infectious and non-infectious mouse models injected intraperitoneally with LPS. Platelets were found to preferentially adhere to mesenchymal cells rather than epithelial cells. BxPC-3 epithelial cells showed upregulation of CD44-variant and epithelial splicing regulatory protein 1 (ESRP-1) expression. However, Panc-1 mesenchymal cells and TGF- $\beta$-treated BxPC-3 cells showed upregulation of CD44-standard and zinc finger E-box-binding homeobox 1 (ZEB-1) expression and a reduction in ESRP-1. In the non-infectious model, cancer cells were not found in the liver. In the infectious model, although epithelial cells without platelet adhesion were in an apoptotic state, mesenchymal cells showed many viable cancer cells
\end{abstract}

Correspondence to: $\mathrm{Dr}$ Mitsuyoshi Okazaki, Department of Gastroenterological Surgery, Division of Cancer Medicine, Graduate School of Medical Science, Kanazawa University, 13-1 Takara-Machi, Kanazawa, Ishikawa 920-8641, Japan

E-mail: mitsuyoshi0610@yahoo.co.jp

Key words: platelet adhesion, innate immune surveillance, CD44 isoform, infectious complication, hematogenous distant metastasis surrounded by activated platelets. Cancer cells were suggested to have phenotypic plasticity through the switching of CD44 isoforms. Mesenchymal cells, which express CD44-standard, could escape from immune surveillance by becoming surrounded by adhered activated platelets. Therefore, it may be necessary to administer antiplatelet agents to prevent distant hematogenous metastasis when post-operative abdominal infectious complications occur.

\section{Introduction}

Cancer is the leading cause of death worldwide, and almost $50 \%$ of all new cancer cases globally were diagnosed in the elderly (1). Despite recent advances in multimodal treatment including surgery, chemotherapy, and radiotherapy, the outcomes of treatment for gastroenterological (GI) cancers remain poor (2).

The impacts of post-operative abdominal infectious complications such as anastomotic leakage and bile leakage increase distant hematogenous metastasis and result in poor long-term survival after curative resection for GI cancers such as colorectal, esophageal, and hepatobiliary cancer (3-7). Traditional ideas propose that these potential mechanisms are involved in the systemic immunosuppressive effects of sepsis and inflammation (3). High levels of interleukin (IL)-1, IL-6, IL-8, and tumor necrosis factor (TNF)- $\alpha$ can decrease the number and function of cytotoxic lymphocytes, natural killer (NK) cells, and dendritic antigens (8-10). These changes promote a direct oncogenic effect, stimulating circulating tumor cell (CTC) adhesion and the development of distant hematogenous metastasis $(11,12)$. CTCs are actively released by the tumor and disseminate through the bloodstream, but the molecular mechanisms of distant hematogenous metastasis have not been fully investigated.

The preferential organ of metastasis is the liver for various GI cancers (13-15). However, the liver is an important organ in immune surveillance (16-18). The immune compartment of the liver harbors diverse innate cell populations such as Kupffer, NK, and gamma delta $(\gamma \delta)$ T cells $(19,20)$. These cells attack bacteria, microbial products, and CTCs, which generally causes distant metastasis failure (21).

Activated platelet-mediated neutrophil extracellular traps (NETs) have gained attention as a host defense response to bacterial infection $(22,23)$. Normally, the liver has no capillary 
structure, so when bacteria reach the liver, they spread throughout the body. Released extracellularly from activated neutrophils in response to both infection and the sterile inflammatory process, NETs form a three-dimensional meshwork that traps and kills cancer cells as well as bacteria within their matrices as part of the host's defense mechanism (22-24). However, excessive NET formation releases anti-microbial granule proteins such as damage-associated molecular patterns (DAMPs) including nuclear protein high mobility group box 1 (HMGB1), histones, and myeloperoxidase, which can lead to tissue and endothelial damage $(23,25)$. NET formation occurs in the sinusoid of the liver and in the alveolar wall of the lung $(26,27)$. We previously demonstrated that progression from sepsis to liver dysfunction, characterized by NETs and activated-platelet aggregation, cause portal hypertension and liver fibrosis, and progress to veno-occlusive disease (VOD) (26). Furthermore, we also reported that these changes in the lung cause pulmonary hypertension, acute lung injury (ALI), and acute respiratory distress syndrome (ARDS) by severe sepsis (27).

Platelets, anucleate hematopoietic cells, cannot be detected by traditional hematoxylin and eosin staining. Therefore, the presence of platelets around primary tumor cells is difficult to recognize. However, activated platelets surrounding CTCs in the cancer microenvironment and immune system have recently gained attention. Placke et al reported that MHC class I present on the cell surface of platelets in blood vessels are transferred to cancer cells, where they directly adhere to CTCs in a cell-cell adhesion manner and surround the CTCs completely, which results in escape from innate immune surveillance (28). Furthermore, we also demonstrated that cancer cells are already surrounded by activated platelets at the primary site before entering blood vessels $(29,30)$. Our study showed that platelet adhesion around cancer cells can be detected both in blood vessels and at the primary site, where they exhibit characteristics of epithelial-mesenchymal transition (EMT) in pancreatic cancer (29). Furthermore, we also reported that cancer cells surrounded by platelets could be associated with EMT and chemoresistance in patients with breast cancer (30).

From these findings, we hypothesized that post-operative abdominal infectious complications could induced NET formation and activated platelet aggression in the liver, which traps CTCs, with CTCs with EMT characteristics escaping from innate immune surveillance through platelet adhesion eventually promoting metastasis. Furthermore, we hypothesized that the switching of CD44 isoforms, which has an important role in EMT, was involved in this process. In the present study, we investigated the association between cancer cells with platelet affinity, EMT, and distant hematogenous metastasis in abdominal infectious complications.

\section{Materials and methods}

Reagents. Transforming growth factor (TGF)- $\beta$ and lipopolysaccharide (LPS) were purchased from Sigma-Aldrich; Merck KGa.

Cell lines and cell culture. The human pancreatic ductal adenocarcinoma (PDAC) cell lines used in this study included Capan-1, BxPC-3, Panc-1, and MiaPaCa-2, which were purchased from American Type Culture Collection
(ATCC). A previous study reported that Capan-1 and BxPC-3 have an epithelial phenotype, while Panc-1 and MiaPaCa-2 have a mesenchymal phenotype (31). We also demonstrated that Capan-1 and BxPC-3 cells can form liver metastases in immunodeficient mice (32). Capan-1 and BxPC-3 were maintained in RPMI-1640 medium supplemented with $10 \%$ fetal bovine serum (FBS; Iwaki, Japan), 2 mM glutamine (Nissui Pharmaceutical, Tokyo, Japan), and $10 \mathrm{U} / \mathrm{ml}$ penicillin-streptomycin (Gibco-BRL; Thermo Fisher Scientific, Inc.). Panc-1 and MIA PaCa-2 cells were maintained in Dulbecco's modified Eagle's medium (DMEM; Gibco-BRL; Thermo Fisher Scientific, Inc.) supplemented with 10\% FBS, glutamine, and penicillin-streptomycin. The cells were seeded in gelatin-coated $75-\mathrm{cm}^{2}$ flasks (BD BioCoat) and cultured in $10 \mathrm{ml}$ medium at $37^{\circ} \mathrm{C}$ in a humidified atmosphere of $5 \% \mathrm{CO}_{2}$. To induce a change from the epithelial to the mesenchymal phenotype, BxPC-3 cells were treated with TGF- $\beta(5 \mathrm{ng} / \mathrm{ml})$ for 28 days and were passaged every 3 days.

Platelet preparation. Blood was obtained from healthy donors who for at least 10 days had not taken medication known to affect platelet function. All healthy donors gave their written informed consent before providing blood samples. Blood was collected by venipuncture through a 19-gauge butterfly needle without a tourniquet to avoid platelet activation. For the preparation of platelet-rich plasma (PRP), blood was collected into a syringe containing $3.2 \%$ trisodium citrate as anticoagulant, then centrifuged at $170 \mathrm{x} \mathrm{g}$ for $10 \mathrm{~min}$ at room temperature. For the preparation of washed platelets, blood was collected into acid-citrate-dextrose (ACD: $38 \mathrm{mM}$ citric acid, $75 \mathrm{mM}$ sodium citrate, $124 \mathrm{mM}$ D-glucose) as anticoagulant. Blood was centrifuged at $170 \mathrm{x}$ g for $10 \mathrm{~min}$ at room temperature. PRP was acidified to pH 6.5 with ACD, and PGE1 (1 mM) was added to avoid platelet activation during centrifugation. Platelets were pelleted by centrifugation at $720 \mathrm{x}$ g for $10 \mathrm{~min}$. The supernatant was removed and the platelet pellet was resuspended in JNL buffer $(130 \mathrm{mM} \mathrm{NaCl}, 10 \mathrm{mM}$ sodium citrate, $9 \mathrm{mM} \mathrm{NaHCO} 3,6 \mathrm{mM}$ D-glucose, and $0.9 \mathrm{mM} \mathrm{MgCl}_{2}$, $0.81 \mathrm{mM} \mathrm{KH}_{2} \mathrm{PO}_{4}$, and $10 \mathrm{mM}$ Tris, $\mathrm{pH}$ 7.4) and supplemented with $1.8 \mathrm{mM} \mathrm{CaCl}_{2}$.

Co-culture with cell lines and PRP. A total of 5.0x $10^{4}$ pancreatic cancer cells were grown on two-well Lab-Tek chamber slides (Thermo Fisher Scientific, Inc.) for $24 \mathrm{~h}$. Then, they were co-cultured with 5.0x10 6 PRP for $24 \mathrm{~h}$. For visualization of activated platelets, cancer cells were fixed in a mixture of methanol and acetone (1:1) for $10 \mathrm{~min}$. Following treatment with protein block serum (Dako Cytomation) for $10 \mathrm{~min}$, the sections were incubated with anti-CD42b antibody (dilution 1:100; cat. no. ab134087; Abcam) at $4^{\circ} \mathrm{C}$ overnight. The Envision-polymer solution (horseradish peroxidase, HRP; Dako Cytomation) was then applied for $1 \mathrm{~h}$. Signals were developed in $0.02 \% 3,3$ '-diaminobenzidinetetrahydrochloride (DAB) solution containing $0.1 \% \mathrm{H}_{2} \mathrm{O}_{2}$. Sections were then lightly counterstained with hematoxylin and examined using a fluorescence microscope (original magnification x400, Olympus, Tokyo, Japan).

Western blotting. Approximately $5 \times 10^{6}$ cells were lysed in RIPA buffer [50 mmol/l Tris- $\mathrm{HCl}$ (pH 8.0), 150 mmol/l sodium 
chloride, $0.5 \mathrm{w} / \mathrm{v} \%$ sodium deoxycholate, $0.1 \mathrm{w} / \mathrm{v} \%$ sodium dodecyl sulfate, and $1.0 \mathrm{w} / \mathrm{v} \%$ NP-40 substitute (Wako)] containing $1 \%$ protease inhibitor cocktail (Sigma-Aldrich; Merck $\mathrm{KGaA}$ ). The protein concentration of each lysate was measured using a BCA protein assay kit (Pierce Biotechnology; Thermo Fisher Scientific, Inc.). Protein from each sample was loaded onto $12.5 \%$ SDS-PAGE gels (Bio-Rad, USA) and subjected to electrophoresis. An amount of $20 \mu \mathrm{g}$ of proteins were transferred to a PVDF membrane (Bio-Rad, USA) and blocked with blocking solution (0.1\% Tween-20; EZ Block ATTO Corp.) at room temperature for $30 \mathrm{~min}$. Blots were incubated overnight at $4^{\circ} \mathrm{C}$ with each primary antibody (see below). The membranes were incubated with IRDye $800 \mathrm{CW}$-conjugated goat anti-mouse IgG (dilution 1:10,000; cat. no. 926-32212; LICOR Bioscience) or IRDye $680 \mathrm{CW}$-conjugated goat anti-rabbit IgG (dilution 1:10,000; cat. no. 926-32213; LICOR Bioscience) for $1 \mathrm{~h}$ at room temperature. The immunoblots were visualized using an ECL Plus western blotting detection system (GE Healthcare Japan Ltd., Japan) and the Light-Capture system (ATTO). To ensure equal protein loading, $\beta$-actin levels were measured using an anti- $\beta$-actin monoclonal antibody (dilution 1:3,000; cat. no. A2228; Sigma-Aldrich; Merck KGa), anti-CD44 variant 6 monoclonal antibody (dilution 1:500; cat. no. ab78960; Abcam), anti-CD44 standard monoclonal antibody (dilution 1:250; cat. no. BBA10; R\&D Systems), anti-ZEB1 monoclonal antibody (dilution 1:500; cat. no. ab203829; Abcam). anti-ESRP-1 polyclonal antibody (RBM35A, dilution 1:500; cat. no. ab107278; Abcam), anti-E-cadherin monoclonal antibody (dilution 1:1,000; cat. no. sc7870; Santa CruzBiotechnology,Inc.), and anti-vimentin monoclonal antibody (dilution 1:1,000; cat. no. sc6260; Santa Cruz Biotechnology, Inc.).

CD44 knockdown. Panc-1 cells were seeded into $75-\mathrm{cm}^{2}$ flasks at a density of $1 \times 10^{6}$ cells $/ \mathrm{ml}$. The next day, the cells were transiently transfected with a short interfering RNA (siRNA) targeting CD44 (30 nM) or negative control siRNA (30 nM; Silencer ${ }^{\circledR}$ Select Negative Control No. 1 siRNA; catalog no. 4390843; Ambion; Thermo Fisher Scientific, Inc.) using Lipofectamine 2000 (Thermo Fisher Scientific, Inc.). The CD44 siRNA sequence was forward, 5'UAUUCCACGUGG AGAAAAATT3' and reverse, 3'UUUUUCUCCACGUGG AAUACA5'. After $72 \mathrm{~h}$, the cells were collected. Fluorescence microscopy was performed to examine cells stained with CD42b, and the expression of CD44s and vimentin was also assessed by western blotting.

Experimental animals. All animal experiments were performed according to the standard guidelines of Kanazawa University. All procedures were in accordance with the Fundamental Guidelines for Proper Conduct of Animal Experiments and Related Activities in Academic Research Institutions, under the jurisdiction of the Ministry of Education, Culture, Sports, Science, and Technology of Japan and with the Helsinki Declaration of 1964 and later versions (https://www.wma. net/policies-post/wma-declaration-of-helsinki-ethical-principlesfor-medical-research-involving-human-subjects/). This study was approved by the Research Ethics Committee of Kanazawa University (AP-163774; Kanazawa, Japan). We used male BALB/c mice (aged 6-10 weeks and weighing 20-22 g; Charles River Laboratories, Kanagawa, Japan) as a sepsis model to observe the aggregation of platelets and metastasis formation in infectious complications. All the animals were housed under specific pathogen-free conditions with a 12 -h dark/light cycle at $25^{\circ} \mathrm{C}$, and fed standard food and aseptic water.

Abdominal infectious model. An abdominal infectious model was prepared as previously described (26). Lipopolysaccharide (LPS) was dissolved in saline and diluted to $0.0003 \mathrm{~g} / \mathrm{ml}$. The solution was administered at a concentration of $1 \mathrm{mg} / \mathrm{kg}$ and injected intraperitoneally into mice. After $24 \mathrm{~h}, 5 \times 10^{6}$ cells $/ 100 \mu \mathrm{l}$ BxPC-3, TGF- $\beta$-treated BxPC-3, and Panc-1 cells were injected into the spleen and the animals were carefully monitored. Intrasplenic injection of cancer cells reproduces circulating tumor cells (CTCs), and a previous study was similarly performed to generate a liver metastasis model (33). At $1 \mathrm{~h}$ following intrasplenic injection of cancer cells, mice were euthanized and analyzed. Mice injected with Panc-1 cells were also euthanized and analyzed at 3 and $6 \mathrm{~h}$ following intrasplenic injection. For the control group, mice were administered $500 \mu 1$ saline intraperitoneally, which represented the non-infectious model.

Immunohistochemistry. Excised organs were fixed in 10\% neutral buffered formalin and embedded in paraffin. The specimens were sliced into $3-\mathrm{mm}$ sections and embedded in paraffin. Each paraffin block was further sliced into $0.5-1-\mu \mathrm{m}$-thick sections and mounted on slides. The expression levels of cytokeratin (mouse monoclonal $\mathrm{IgG}$, dilution 1:50; Abcam) to detect the presence of human cytoplasm, p-selectin (mouse monoclonal IgG, dilution 1:100; Abcam) to examine the presence of activated platelets and hepatic sinusoid endothelial cells, and mab4383 (mouse monoclonal IgG, dilution 1:200; EMD Millipore) to examine the presence of nuclei of human cell types were assessed by immunohistochemistry. Deparaffinized sections were pretreated by autoclaving in $10 \%$ citric acid buffer $(\mathrm{pH} 8.0)$ at $120^{\circ} \mathrm{C}$ for $15 \mathrm{~min}$. Following treatment with protein block serum (Dako Cytomation) for 10 min and incubation with $2 \%$ skim milk for 30 min to block non-specific reactions, the sections were incubated with primary antibody at $4^{\circ} \mathrm{C}$ overnight. Envision-polymer solution (horseradish peroxidase, HRP; Dako Cytomation) was then applied for $1 \mathrm{~h}$. Signals were developed in 0.02\% 3,3'-diaminobenzidine tetrahydrochloride (DAB) solution containing $0.1 \%$ $\mathrm{H}_{2} \mathrm{O}_{2}$. Sections were then lightly counterstained with hematoxylin and examined using a fluorescence microscope (original magnification $x 400$, Olympus, Tokyo, Japan). The number of Panc-1 cells positively stained by mab4383 was calculated by counting within the original field of magnification at $\mathrm{x} 40$ at 1,3 , and $6 \mathrm{~h}$ following intrasplenic injection.

Statistical analysis. Values are expressed as mean \pm SD. Comparisons were made using one-way analysis of variance or Student's t-test followed by Tukey's post hoc test using SPSS statistical software, version 11.0 (IBM, Corp.). P-values $<0.05$ indicated a statistically significant difference.

\section{Results}

Platelet adhesion to pancreatic cancer cells. Capan-1 and BxPC-3 cells showed slight platelet adhesion and cell-to-cell 


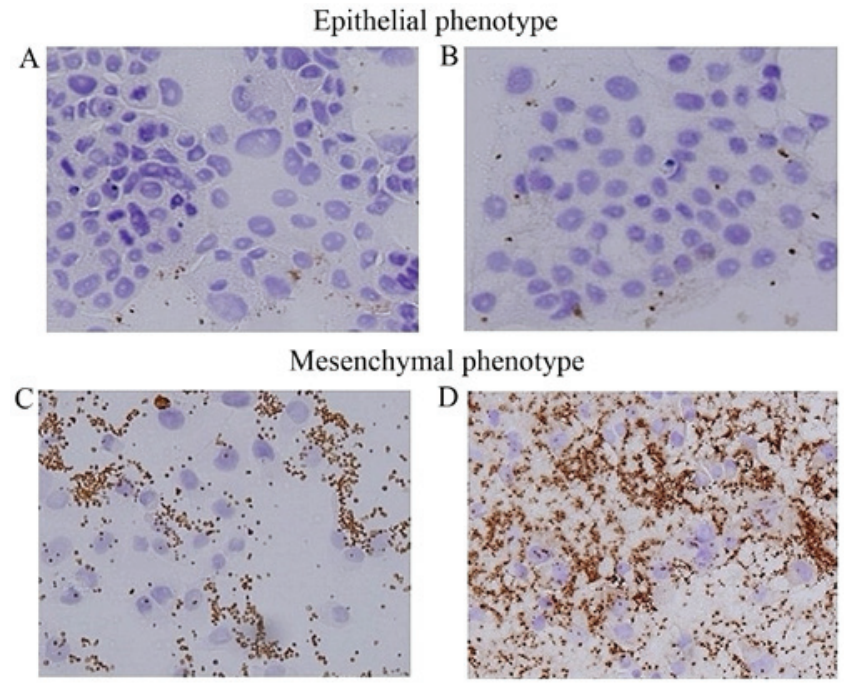

Figure 1. Immunocytochemical analysis of CD42b for examination of platele adhesion. Epithelial phenotype cancer cells (A, Capan-1; B, BxPC-3) showed slight platelet adhesion. Mesenchymal phenotype cancer cells (C, Panc-1; D, MiaPaca-2) were surrounded by many activated platelets (original magnification $\mathrm{x} 400$ ). CD42b, cluster of differentiation $42 \mathrm{~b}$.

adhesion (Fig. 1A and B), while Panc-1 and MiaPaca-2 cells showed loss of cell-to-cell adhesion and were completely surrounded by many activated platelets, which were positive for CD42b staining (Fig. 1C and D). Based on these results, we decided to use BxPc-3 cells as the epithelial cancer cell line, and Panc-1 cells as the mesenchymal cancer cell line in subsequent experiments.

Adhesion molecules influenced by EMT. A panel of PDAC cell lines was examined by western blotting for the expression of CD44 isoforms, transcriptional factors, and EMT markers. BxPC-3 cells showed a reduction in vimentin and upregulation of E-cadherin expression, and Panc-1 cells showed reduction in E-cadherin and upregulation of vimentin expression. TGF- $\beta$-mediated BxPC-3 showed the same findings as Panc-1 and demonstrated a change from an epithelial phenotype to a mesenchymal phenotype. Furthermore, western blotting identified a reduction in CD44-standard and zinc finger E-box-binding homeobox 1 (ZEB-1) and upregulation of CD44-variant6 and epithelial splicing regulatory protein 1 (ESRP-1) expression in BxPC-3 cells. However, Panc- 1 and TGF- $\beta$-treated BxPC-3 cells were identified as having reduced CD44-variant 6 and ESRP-1, and upregulation of CD44-standard and ZEB-1 expression (Fig. 2). Blots were re-probed for $\beta$-actin to ensure equal protein loading in each lane. Results are representative data from three separate experiments.

Platelet adhesion to TGF- $\beta$-treated BxPC-3. BxPC-3 cells showed slight platelet adhesion and cell-to-cell adhesion (Fig. 3A), while TGF- $\beta$-treated BxPC-3 cells were demonstrated to show more preferential platelet adhesion than BxPC-3 cells and loss of cell-to-cell adhesion (Fig. 3B). In other words, switching CD44 from the variant isoform to the standard isoform through EMT changed the affinity for platelets.

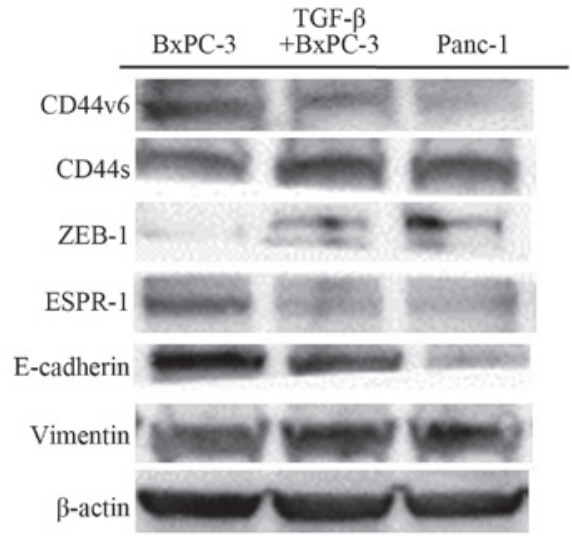

Figure 2. Western blot analysis of CD44v6, CD44s, ZEB-1, ESRP-1, E-cadherin, vimentin, and $\beta$-actin in BxPC-3, TGF- $\beta$-treated BxPC-3, and Panc- 1 cells. The average signal intensity was standardized to that of $\beta$-actin. CD44v6, CD44-version 6; CD44s, CD44-standard; ZEB-1, zinc finger E-box-binding homeobox 1; ESRP-1, epithelial splicing regulatory protein 1.
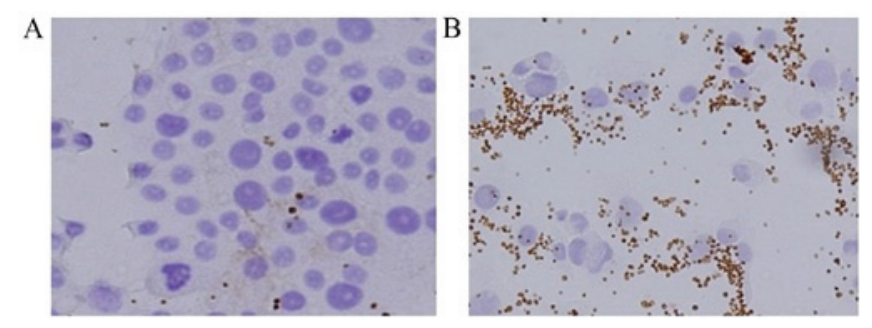

Figure 3. Immunocytochemical analysis of CD42b for examination of platelet adhesion. BxPC-3 cells (A) showed slight platelet adhesion. TGF- $\beta$-treated BxPC-3 cells (B) were surrounded by many activated platelets (original magnification $\mathrm{x} 400)$. CD42b, cluster of differentiation $42 \mathrm{~b}$.

Effect of CD44 knockdown by CD44 siRNA. Panc-1 and control siRNA-treated Panc-1 cells preferentially adhered to platelets, which were positive for CD42b staining (Fig. 4A and C), while CD44 siRNA-treated Panc-1 cells showed slight platelet adhesion (Fig. 4B). In western blotting, Panc-1 cells showed upregulated CD44s and vimentin expression, while CD44 siRNA-treated Panc-1 cells demonstrated a reduction in CD44s and vimentin expression (Fig. 5). These findings suggested that $C D 44$ knockdown by $C D 44$ siRNA could change the mesenchymal phenotype and reduce the affinity of cancer cells for platelets.

Mab4383 expression for examination of cancer cell viability. In the liver of the non-infectious model, a small number of Panc-1 cells was identified. In the liver of the abdominal infectious model, positive staining for mab4383 was higher than that in the non-infectious model. In both models, Panc-1 cells showed a gradual decrease in number (Fig. 6A), while there were significantly more Panc-1 cells in the infectious models than in the non-infectious models at all times (Fig. 6B).

Cytokeratin expression for examination of cancer cell viability. In the liver of the non-infectious model, cancer cells were not found regardless of the cancer cell line type (data not shown). In the liver of the abdominal infectious model, positive 


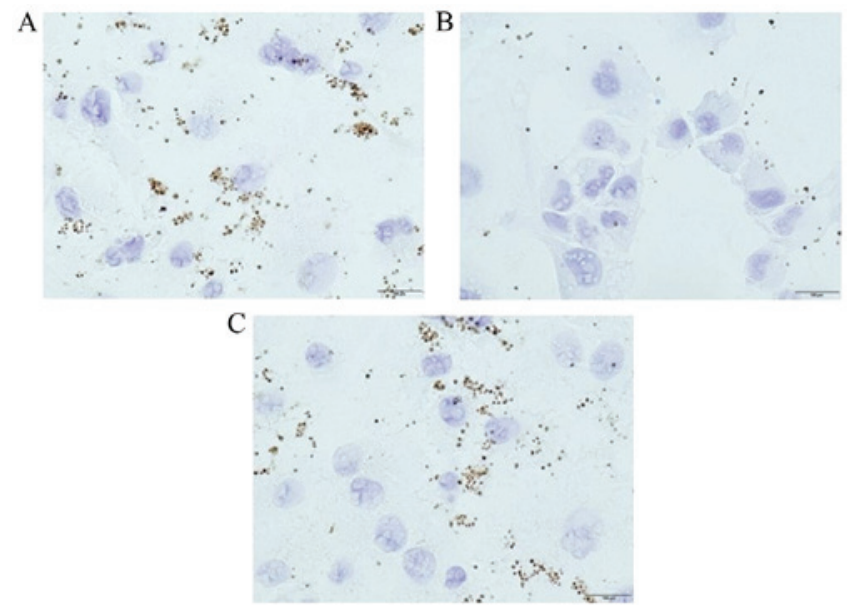

Figure 4. Immunocytochemical analysis of CD42b for examination of CD44 knockdown by CD44 siRNA. Panc-1 (A) and control siRNA-treated Panc-1 cells (C) were preferentially adherent to platelets. CD44 siRNA-treated Panc-1 cells (B) showed slight platelet adhesion (original magnification $\mathrm{x} 400$ ). CD42b, cluster of differentiation $42 \mathrm{~b}$.

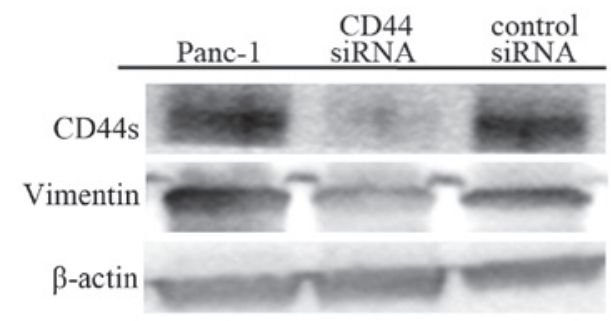

Figure 5. Western blot analysis of CD44s, vimentin, and $\beta$-actin in Panc- 1 , control siRNA-treated Panc-1 and CD44 siRNA-treated Panc-1 cells. The average signal intensity was standardized to that of $\beta$-actin. CD44s, CD44-standard.

staining for cytokeratin was weak in the specimens regardless of the cancer cell line type (Fig. 7). There were very few viable BxPC-3 cells, epithelial phenotype cancer cells, because the nuclei were deformed and there were few circular cells, with most cells in an apoptotic state (Fig. 7A and D). Conversely, there were some viable TGF- $\beta$-treated BePC-3 (Fig. 7B and E) and Panc-1 cells (Fig. 7C and F) and mesenchymal phenotype cells, as shown by cytokeratin staining, which formed a focal cluster within the liver sinusoid.

P-selectin expression for examination of platelet adhesion. In the liver of the non-infectious model, activated platelets were not observed, while a few activated hepatic sinusoid endothelial cells were observed (data not shown). In the liver of the abdominal infectious model, activated sinusoidal endothelial cells stained with p-selectin were observed more frequently than in the non-infectious model (Fig. 8). In cancer cells with the epithelial phenotype (BxPC-3 cells), very few viable cells were surrounded by activated platelets stained with p-selectin, while apoptotic cancer cells were not surrounded by activated platelets (Fig. 8A and D). Conversely, some viable mesenchymal phenotype cancer cells [TGF- $\beta$-treated BePC-3 (Fig. 8B and E) and Panc-1 cells (Fig. 8C and F)] were completely surrounded by adherent platelets.
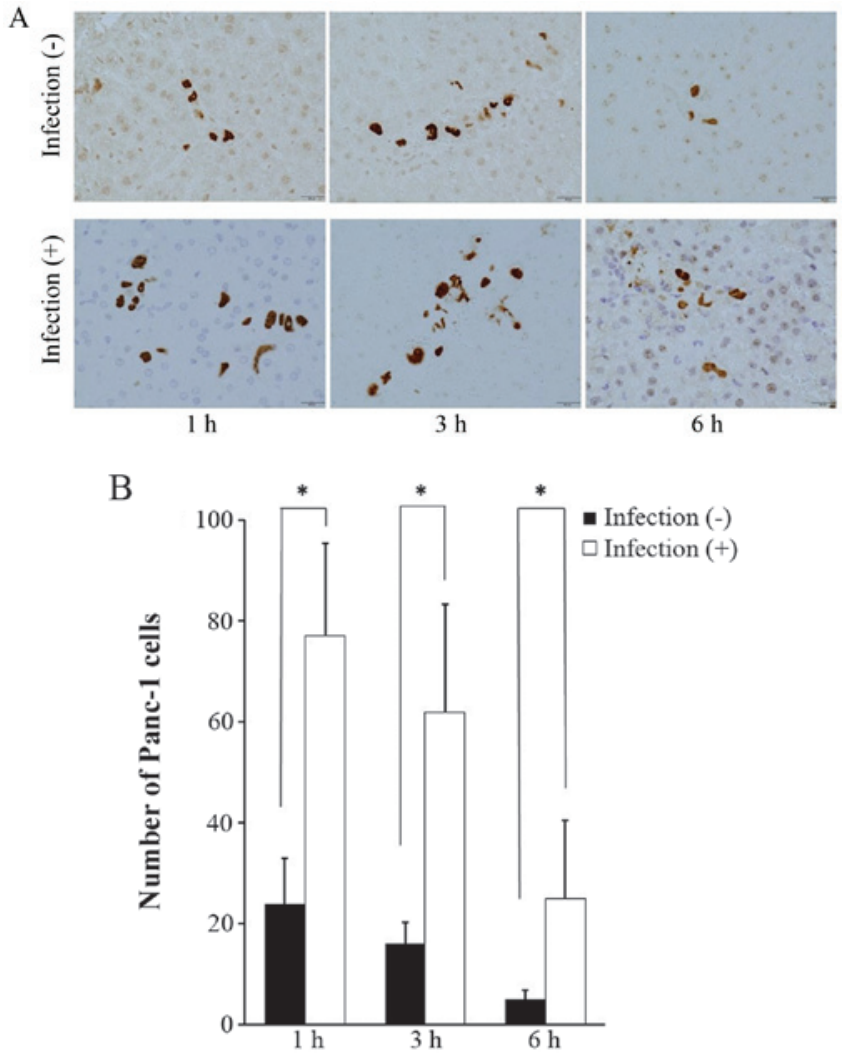

Figure 6. Immunocytochemical analysis of mab4383 for examination of Panc- 1 cells. (A) Panc-1 cells stained by mab4383 showed a gradual decrease in number in both models (original magnification $x 40$ ). (B) There were significantly more Panc-1 cells in the infectious model than in the non-infectious models at all times. Results represent the mean \pm SD of five experiments. ${ }^{*} \mathrm{P}<0.05$. Infection(-), non-infectious model; Infection(+), infectious model. Results are mean \pm SD of five experiments.

\section{Discussion}

Human cancer cells are generally recognized as xenogeneic and exogenous material and cannot be engrafted in immunocompetent mice because of innate immune surveillance. However, our study demonstrated that cancer cells which adhered to activated platelets were viable in the abdominal infectious model at $1 \mathrm{~h}$ following intrasplenic injection of cancer cells. Additionally, cells with the mesenchymal phenotype, Panc-1 and TGF- $\beta$-treated BxPC-3 cells, which express the CD $44 \mathrm{~s}$ isoform, clearly showed these changes. Therefore, our study confirmed that escape from innate immune surveillance was induced by the enhanced adhesion of activated platelets by epithelial-mesenchymal transition (EMT) and switching of CD44 from the variant to the standard isoform.

Circulating tumor cells (CTCs) are present in advanced GI cancer patients including those presenting with esophageal (34), colorectal (35-38), and pancreatic cancer $(39,40)$. Cancer metastasis formation in animal studies is promoted by injecting cancer cells into blood vessels (33). Tien et al reported that CTCs in the portal vein were detected in 58.3\% of patients with periampullary or pancreatic carcinoma undergoing pancreaticoduodenectomy. Furthermore, $28.3 \%$ of patients had liver metastases within 6 months after surgery, and liver metastases developed soon after surgery in patients with a high portal venous CTC count (41). Most CTCs are 

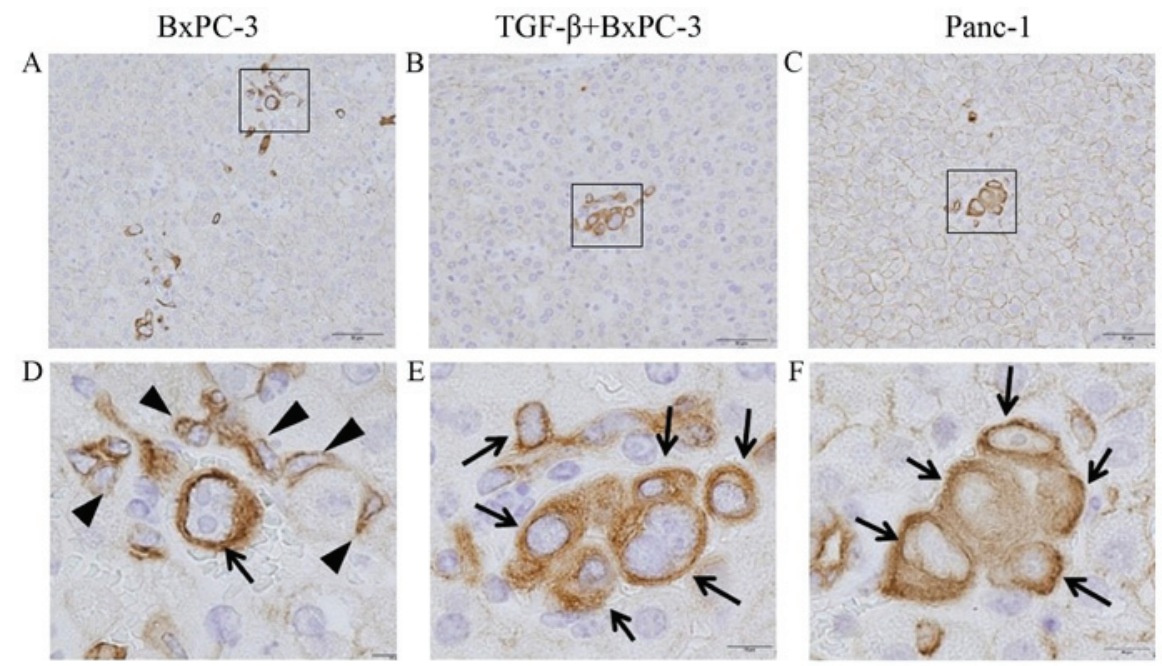

Figure 7. Immunohistochemical analysis of cytokeratin in the infectious model. BxPC-3 cells (A and D) showed few viable cancer cells (arrows) and many apoptotic cancer cells (arrowheads). TGF- $\beta$-treated BxPC-3 (B and E) and Panc-1 cells (C and F) showed some viable cancer cells forming a cluster (arrows). A-C, original magnification $\times 200$; D-F, original magnification $\times 1,000$. TGF- $\beta$, transforming growth factor- $\beta$.
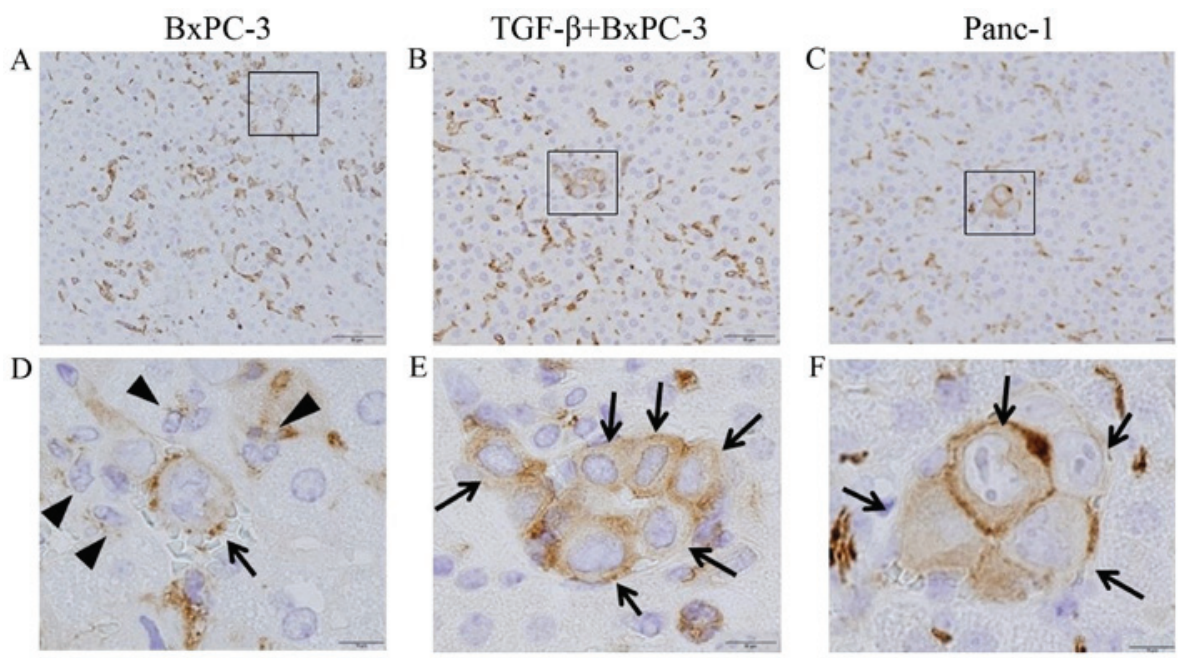

Figure 8. Immunohistochemical analysis of p-selectin in the infectious model. BxPC-3 cells showed slight activated platelet adhesion around viable cancer cells (arrow), but platelet adhesion around apoptotic cancer cells was not evident (arrowheads; A and D). TGF- $\beta$-treated BxPC-3 (B and E) and Panc-1 (C and F) showed platelet adhesion around viable cancer cells (arrows). A-C, original magnification $\mathrm{x} 200$; D-F, original magnification $\mathrm{x} 1,000$. TGF- $\beta$, transforming growth factor- $\beta$.

eliminated by immune cells such as natural killer (NK) cells, but pathophysiologically, cancer metastasis formation from CTCs has not been fully elucidated.

Previous studies reported that neutrophil extracellular traps (NETs) have strong adhesive properties, which enable them to bind to pathogens including CTCs in blood vessels, and that they have important roles in tumor progression and metastasis $(24,33,42)$. We previously demonstrated that aggregated platelets are surrounded by NETs in hepatic sinusoids in the abdominal infectious model using mice intraperitoneally injected with LPS (26). In other words, NETs interact with platelets and leukocytes and are pro-thrombotic, acting as three-dimensional frameworks for both fibrin deposition and later stabilization of thrombi; thus, we named them 'immune-thrombosis' (43-45). Immune-thrombosis comprising NETs and aggregated platelets can trap CTCs, but have some disadvantages including not only endothelial cell damage and detachment through alarmins, including HMGB1 and histones, but also the release of various cytokines and chemokines including TGF- $\beta$, vascular endothelial growth factor-A (VEGF-A) and plasminogen activator inhibitor-1 (PAI-1), which affect cancer progression $(23,25)$. Based on these mechanisms, we postulated that the hepatic sinusoids had already undergone pre-metastatic niche formation in abdominal infectious complications, where they contribute to binding CTCs, which likely results in metastasis.

Activated platelets express p-selectin on their cell surface and can adhere to CD44, a ligand of p-selectin (28). CD44 is also an adhesion molecule and is involved in cell-to-cell and cell-to-matrix adhesion, cell proliferation, differentiation and trafficking, and is highly expressed on stem cells $(46,47)$. CD44 is encoded by 20 exons and undergoes extensive alternative splicing to generate CD44 standard (CD44s) and CD44 variant (CD44v) forms. Zhao et al reported that cells expressing high 
levels of CD44 predominantly showed the CD44s isoform, displayed a mesenchymal phenotype, and were highly invasive, while epithelial phenotype cell lines expressed CD44v (31). Our findings are also in agreement with this previous report and demonstrate that epithelial phenotype cell lines express CD44v and ESRP-1, the latter of which is suppressed by ZEB-1, and mesenchymal phenotype cell lines express CD44s and ZEB-1, which is an EMT-associated transcription factor. EMT is involved in invasion and tumor metastasis is a property of stem cells, whereas, mesenchymal-to-epithelial (MET) switch may favor tumor growth (48). Cancer cells have phenotypic plasticity, which confers survival capabilities through phenotypic changes induced by EMT and MET in response to various environmental factors. CD44 may have a role in regulating these processes.

In the present study, cells with a mesenchymal phenotype and expressing CD44s were more preferentially adherent to activated platelets than cells with an epithelial phenotype that expressed CD44v. We also found that BxPC-3 cells could switch CD44 isoforms from the variant to the standard isoform through EMT via TGF- $\beta$ and a reduction in ESRP-1 and that TGF- $\beta$-treated BxPC- 3 cells were preferentially adherent to activated platelets. Furthermore, we demonstrated that $C D 44$ knockdown by $C D 44$ siRNA resulted in a reduction in platelet adhesion. From these findings, cancer cells are suggested to have phenotypic plasticity. In particular, we hypothesized that CD44s is involved in cluster formation via platelet adhesion and enhanced platelet adhesion contributes to escape from innate immune surveillance. A previous study reported that EMT indeed provides epithelial tumor cells with enhanced migratory, invasive, and survival abilities that enable them to participate in the liberation of CTCs into blood vessels (49-51). CTCs may be able to travel in the blood vessels as clusters or microemboli to escape innate immune surveillance, and therefore have higher metastatic potential.

Our study demonstrated the escape from innate immune surveillance through activated platelet adhesion using an infectious mouse model by injecting LPS intraperitoneally into mice. In the non-infectious model, which has no NET formation in the liver, we did not identify viable cancer cells in the liver sinusoid, regardless of the epithelial or mesenchymal phenotype. In the infectious model, which has NET formation in the liver, epithelial cancer cells such as BePC-3 had slight platelet adhesion and were mostly in an apoptotic state. However, mesenchymal cancer cells such as Panc-1 and TGF- $\beta$-treated BxPC- 3 cells had abundant platelet adhesion and formed clusters and were in a viable state at $1 \mathrm{~h}$ following intrasplenic injection of cancer cells despite the xenogeneic and exogenous material in immunocompetent mice. To summarize, when cancer cells express $\mathrm{CD} 44 \mathrm{v}$ and have an epithelial phenotype, they are not trapped by immune thrombosis because of the reduced platelet adhesion, and are recognized as non-self by immunocompetent cells, which results in an apoptotic state induced by the innate immune surveillance. However, when cancer cells express CD44s and have a mesenchymal phenotype, they are trapped by immune thrombosis and form clusters due to the upregulated platelet adhesion and are recognized as self by MHC class I present on the cell surface of platelets. Consequently, these cells can escape from innate immune surveillance of immunocompetent cells and liver metastasis develops (28). From these findings, we suspect that this process is the initial invasion step. Literature reporting xenografts in animal models has suggested that CTC clusters have higher metastatic potential than single CTCs (52). Furthermore, Yu et al reported that CTCs of breast cancer expressing a mesenchymal phenotype predominantly formed multicellular clusters surrounded by platelets (53). Though innate immune surveillance was not examined in this study, these findings agree with our results and support the idea that platelet adhesion could also have a role in the survival of CTCs.

Our study results suggest that NET formation and platelet adhesion may be potential therapeutic targets not only in sepsis but also in cancer progression (41). In previous studies, Yu et al reported that aspirin therapy, which is an antiplatelet agent in patients with acute respiratory distress syndrome (ARDS)/acute lung injury (ALI), was associated with reduced incidence rate (54), while Boyle et al reported that aspirin is associated with reduced intensive care unit mortality (55). Furthermore, recent reports suggest that aspirin prevents distant metastasis; this could account for the reduction in cancer deaths (56-58). These studies showed that platelets have an important function in the progression of ARDS/ALI and cancer, but there is no detailed mechanism of platelet association such as escape from innate immune surveillance. We previously reported that the antiplatelet agent cilostazol could inhibit NET formation in a monocrotaline-induced model (59). Our data in the present study suggested a potential role for antiplatelet agents in suppressing NET formation and immune surveillance in the tumor microenvironment.

In conclusion, abdominal infectious complications induced NET formation and immune-thrombosis in the liver sinusoids. Cancer cells have phenotypic plasticity that is adapted for various environments by switching CD44 isoform and changing the affinity for platelets. CTC clusters surrounded by activated platelets, especially those more preferentially adherent to CD44s, as well as mesenchymal phenotype cancer cells, could escape from immune surveillance, which results in the first step of cancer metastasis formation. In the progression of distant hematogenous metastasis, it is important that not just NETs but also activated platelet aggregates escape from innate immune surveillance. We are now conducting research to elucidate the mechanisms of MHC class I molecules in NETs and activated platelet aggregates. We believe that it may be necessary to undertake treatment management including administration of antiplatelet agents to prevent distant hematogenous metastasis in GI cancer patients with post-operative abdominal infectious complications.

\section{Acknowledgements}

We are grateful to members of the Department of Gastroenterological Surgery of Kanazawa University for their helpful suggestions.

\section{Funding}

No funding was received.

\section{Availability of data and materials}

All data generated or analyzed during the present study are included in this published article. 


\section{Authors' contributions}

MO, TY and TO contributed to the conception and design of the study, as well as data acquisition and interpretation. MO and TY drafted the manuscript. HT and SF analyzed and interpret the data, and critically reviewed the manuscript. TO supervised and also conceived and designed the study. All authors contributed to the interpretation of the findings, and reviewed, edited, and approved the final manuscript.

\section{Ethics approval and consent to participate}

The study was approved by the Research Ethics Committee of Kanazawa University (AP-163774; Kanazawa, Japan). All procedures followed were in accordance with the Fundamental Guidelines for Proper Conduct of Animal Experiments and RelatedActivitiesinAcademicResearchInstitutions(http://www. clar.med.tohoku.ac.jp/data/kitei/10th/hoi1-10th-E-monkashou. pdf\#search='Fundamental+Guidelines+for+Proper+Conduct+of +Animal+Experiments+and+Related+Activities+in+Academic +Research+Institutions').

\section{Patient consent for publication}

Not applicable.

\section{Competing interests}

The authors declare that they have no competing interests.

\section{References}

1. Pilleron S, Sarfati D, Janssen-Heijnen M, Vignat J, Ferlay J, Bray F and Soerjomataram I: Global cancer incidence in older adults, 2012 and 2035: A population-based study. Int J Cancer 144: 49-58, 2019.

2. Carioli G, Malvezzi M, Bertuccio P, Hashim D, Waxman S, Negri E, Boffetta P and La Vecchia C: Cancer mortality in the elderly in 11 countries worldwide, 1970-2015. Ann Oncol 30: 1344-1355, 2019.

3. Farid SG, Aldouri A, Morris-Stiff G, Khan AZ, Toogood GJ, Lodge JP and Prasad KR: Correlation between postoperative infective complications and long-term outcomes after hepatic resection for colorectal liver metastasis. Ann Surg 251: 91-100, 2010.

4. Ito H, Are C, Gonen M, D'Angelica M, Dematteo RP, Kemeny NE, Fong Y, Blumgart LH and Jarnagin WR: Effect of postoperative morbidity on long-term survival after hepatic resection for metastatic colorectal cancer. Ann Surg 247: 994-1002, 2008.

5. Kataoka K, Takeuchi H, Mizusawa J, Igaki H, Ozawa S, Abe T, Nakamura K, Kato K, Ando N and Kitagawa Y: Prognostic impact of postoperative morbidity after esophagectomy for esophageal cancer: Exploratory analysis of JCOG9907. Ann Surg 265: 1152-1157, 2017.

6. Lerut T, Moons J, Coosemans W, Van Raemdonck D, De Leyn P, Decaluwé H, Decker G and Nafteux P: Postoperative complications after transthoracic esophagectomy for cancer of the esophagus and gastroesophageal junction are correlated with early cancer recurrence: Role of systematic grading of complications using the modified Clavien classification. Ann Surg 250: 798-807, 2009.

7. Braunwarth E, Primavesi F, Göbel G, Cardini B, Oberhuber R, Margreiter C, Maglione M, Schneeberger S, Öfner D and Stättner S: Is bile leakage after hepatic resection associated with impaired long-term survival? Eur J Surg Oncol 45: 1077-1083, 2019.

8. Dranoff G: Cytokines in cancer pathogenesis and cancer therapy. Nat Rev Cancer 4: 11-22, 2004.

9. Ogura M, Takeuchi H, Kawakubo H, Nishi T, Fukuda K, Nakamura R, Takahashi T, Wada N, Saikawa Y, Omori T, et al: Clinical significance of CXCL-8/CXCR-2 network in esophageal squamous cell carcinoma. Surgery 154: 512-520, 2013.
10. Okamura A, Takeuchi H, Matsuda S, Ogura M, Miyasho T, Nakamura R, Takahashi T, Wada N, Kawakubo H, Saikawa Y, et al: Factors affecting cytokine change after esophagectomy for esophageal cancer. Ann Surg Oncol 22: 3130-3135, 2015.

11. Pachot A, Cazalis MA, Venet F, Turrel F, Faudot C, Voirin N, Diasparra J, Bourgoin N, Poitevin F, Mougin B, et al: Decreased expression of the fractalkine receptor CX3CR1 on circulating monocytes as new feature of sepsis-induced immunosuppression. J Immunol 180: 6421-6429, 2008.

12. Panis Y, Ribeiro J, Chrétien Y and Nordlinger B: Dormant liver metastases: An experimental study. Br J Surg 79: 221-223, 1992.

13. Hackl C, Neumann P, Gerken M, Loss M Klinkhammer-Schalke M and Schlitt HJ: Treatment of colorectal liver metastases in Germany: A ten-year population-based analysis of 5772 cases of primary colorectal adenocarcinoma. BMC Cancer 14: 810, 2014.

14. Liu J and Chen L: Current status and progress in gastric cancer with liver metastasis. Chin Med J (Engl) 124: 445-456, 2011.

15. Murakami Y, Satoi S, Sho M, Motoi F, Matsumoto I, Kawai M, Honda G, Uemura K, Yanagimoto H, Shinzeki M, et al: National comprehensive cancer network resectability status for pancreatic carcinoma predicts overall survival. World J Surg 39: 2306-2314, 2015.

16. Krenkel $\mathrm{O}$ and Tacke F: Liver macrophages in tissue homeostasis and disease. Nat Rev Immunol 17: 306-321, 2017.

17. Guilliams M, Dutertre CA, Scott CL, McGovern N, Sichien D, Chakarov S, Van Gassen S, Chen J, Poidinger M, De Prijck S, et al: Unsupervised high-dimensional analysis aligns dendritic cells across tissues and species. Immunity 45: 669-684, 2016.

18. Nolan JP: The role of intestinal endotoxin in liver injury: A long and evolving history. Hepatology 52: 1829-1835, 2010.

19. Crispe IN: The liver as a lymphoid organ. Annu Rev Immunol 27: 147-163, 2009.

20. Jenne $C N$ and Kubes P: Immune surveillance by the liver. Nat Immunol 14: 996-1006, 2013.

21. Davies LC, Jenkins SJ, Allen JE and Taylor PR: Tissue-resident macrophages. Nat Immunol 14: 986-995, 2013.

22. Brinkmann V, Reichard U, Goosmann C, Fauler B, Uhlemann Y, Weiss DS, Weinrauch Y and Zychlinsky A: Neutrophil extracellular traps kill bacteria. Science 303: 1532-1535, 2004.

23. Brinkmann V and Zychlinsky A: Neutrophil extracellular traps: Is immunity the second function of chromatin? J Cell Biol 198: 773-783, 2012.

24. Erpenbeck L and Schön MP: Neutrophil extracellular traps: Protagonists of cancer progression? Oncogene 36: 2483-2490, 2017.

25. Chen R, Kang R, Fan XG and Tang D: Release and activity of histone in diseases. Cell Death Dis 5: e1370, 2014.

26. Sakurai K, Miyashita T, Okazaki M, Yamaguchi T, Ohbatake Y, Nakanuma S, Okamoto K, Sakai S, Kinoshita J, Makino I, et al: Role for neutrophil extracellular traps (NETs) and platelet aggregation in early sepsis-induced hepatic dysfunction. In Vivo 31: 1051-1058, 2017.

27. Miyashita T, Ahmed AK, Nakanuma S, Okamoto K, Sakai S, Kinoshita J, Makino I, Nakamura K, Hayashi H, Oyama K, et al: A three-phase approach for the early identification of acute lung injury induced by severe sepsis. In Vivo 30: 341-349, 2016.

28. Placke T, Örgel M, Schaller M, Jung G, Rammensee HG, Kopp HG and Salih HR: Platelet-derived MHC class I confers a pseudonormal phenotype to cancer cells that subverts the antitumor reactivity of natural killer immune cells. Cancer Res 72: 440-448, 2012

29. Miyashita T, Tajima H, Makino I, Nakagawara H, Kitagawa H, Fushida S, Harmon JW and Ohta T: Metastasis-promoting role of extravasated platelet activation in tumor. J Surg Res 193: 289-94, 2015.

30. Ishikawa S, Miyashita $\mathrm{T}$, Inokuchi M, Hayashi $\mathrm{H}$, Oyama K, Tajima H, Takamura H, Ninomiya I, Ahmed AK, Harman JW, et al: Platelets surrounding primary tumor cells are related to chemoresistance. Oncol Rep 36: 787-774, 2016.

31. Zhao S, Chen C, Chang K, Karnad A, Jagirdar J, Kumar AP and Freeman JW: CD44 expression level and isoform contributes to pancreatic cancer cell plasticity, invasiveness, and response to therapy. Clin Cancer Res 15: 5592-5604, 2016.

32. Ohta T, Nakagawara H, Arakawa H, Futagami F, Tsukioka Y, Kitagawa $\mathrm{H}$, Kayahara M, Nagakawa T and Miyazaki I: A new strategy for the therapy of pancreatic cancer invasion and metastasis by protease inhibitor and protein pump inhibitor agents. Jpn J Gastroenterol Surg 29: 888-892, 1996. 
33. Cools-Lartigue J, Spicer J, McDonald B, Gowing S, Chow S, Giannias B, Bourdeau F, Kubes P and Ferri L: Neutrophil extracellular traps sequester circulating tumor cells and promote metastasis. J Clin Invest 123: 3446-3458, 2013.

34. Qiao Y, Li J, Shi C, Wang W, Qu X, Xiong M, Sun Y, Li D, Zhao $X$ and Zhang D: Prognostic value of circulating tumor cells in the peripheral blood of patients with esophageal squamous cell carcinoma. Onco Targets Ther 10: 1363-1373, 2017.

35. Cohen SJ, Punt CJ, Iannotti N, Saidman BH, Sabbath KD, Gabrail NY, Picus J, Morse M, Mitchell E, Miller MC, et al: Relationship of circulating tumor cells to tumor response, progression-free survival, and overall survival in patients with metastatic colorectal cancer. J Clin Oncol 26: 3213-3221, 2008.

36. Groot Koerkamp B, Rahbari NN, Büchler MW, Koch M and Weitz J: Circulating tumor cells and prognosis of patients with resectable colorectal liver metastases or widespread metastatic colorectal cancer: A meta-analysis. Ann Surg Oncol 20 2156-2165, 2013.

37. Rahbari NN, Aigner M, Thorlund K, Mollberg N, Motschall E, Jensen K, Diener MK, Büchler MW, Koch M and Weitz J: Meta-analysis shows that detection of circulating tumor cells indicates poor prognosis in patients with colorectal cancer. Gastroenterology 138: 1714-1726, 2010.

38. Negin BP and Cohen SJ: Circulating tumor cells in colorectal cancer: Past, present, and future challenges. Curr Treat Options Oncol 11: 1-13, 2010.

39. Dotan E, Alpaugh RK, Ruth K, Negin BP, Denlinger CS, Hall MJ, Astsaturov I, McAleer C, Fittipaldi P, Thrash-Bingham C, et al: Prognostic significance of MUC-1 in circulating tumor cells in patients with metastatic pancreatic adenocarcinoma. Pancreas 45 : $1131-1135,2016$.

40. Kurihara T, Itoi T, Sofuni A, Itokawa F, Tsuchiya T, Tsuji S, Ishii K, Ikeuchi N, Tsuchida A, Kasuya K, et al: Detection of circulating tumor cells in patients with pancreatic cancer: A preliminary result. J Hepatobiliary Pancreat Surg 15: 189-195, 2008.

41. Tien YW, Kuo HC, Ho BI, Chang MC, Chang YT, Cheng MF, Chen HL, Liang TY, Wang CF, Huang CY, et al: A high circulating tumor cell count in portal vein predicts liver metastasis from periampullary or pancreatic cancer: A high portal venous CTC count predicts liver metastases. Medicine (Baltimore) 95: e3407, 2016

42. Richardson JJR, Hendrickse C, Gao-Smith F and Thickett DR: Neutrophil extracellular trap production in patients with colorectal cancer in vitro. Int J Inflam 2017: 4915062, 2017.

43. Engelmann B and Massberg S: Thrombosis as an intravascular effector of innate immunity. Nat Rev Immunol 13: 34-45, 2013.

44. Nakanuma S, Miyashita T, Hayashi H, Tajima H, Takamura H Tsukada T, Okamoto K, Sakai S, Makino I, Kinoshita J, et al: Extravasated platelet aggregation in liver zone 3 may correlate with the progression of sinusoidal obstruction syndrome following living donor liver transplantation: A case report. Exp Ther Med 9: 1119-1124, 2015.

45. Miyashita T, Nakanuma S, Ahmed AK, Makino I, Hayashi H, Oyama K, Nakagawara $H$, Tajima $H$, Takamura $H$, Ninomiya I, et al: Ischemia reperfusion-facilitated sinusoidal endothelial cell injury in liver transplantation and the resulting impact of extravasated platelet aggregation. Eur Surg 48: 92-98, 2016.
46. Keysar SB and Jimeno A: More than markers: Biological significance of cancer stem cell-defining molecules. Mol Cancer Ther 9: 2450-2457, 2010 .

47. Zoller M: CD44: Can a cancer-initiating cell profit from an abundantly expressed molecule? Nat Rev Cancer 11: 254-267, 2011.

48. Brabletz T: EMT and MET in metastasis: Where are the cancer stem cells? Cancer Cell 22: 699-701, 2012.

49. Alix-Panabières C,MaderS and PantelK:Epithelial-mesenchymal plasticity in circulating tumor cells. J Mol Med (Berl) 95: 133-142, 2017.

50. Bourcy M, Suarez-Carmona M, Lambert J, Francart ME, Schroeder H, Delierneux C, Skrypek N, Thompson EW, Jérusalem G, Berx G, et al: Tissue factor induced by epithelial-mesenchymal transition triggers a procoagulant state that drives metastasis of circulating tumor cells. Cancer Res 76: 4270-4282, 2016

51. Cortés-Hernández LE, Eslami-S Z and Alix-Panabières C: Circulating tumor cells as the functional aspect of liquid biopsy to understand the metastatic cascade in solid cancer. Mol Aspects Med 72: 100816, 2020.

52. Aceto N, Toner M, Maheswaran S and Haber DA: En route to metastasis: Circulating tumor cell clusters and epithelial-to-mesenchymal transition. Trends Cancer 1: 44-52, 2015.

53. Yu M, Bardia A, Wittner BS, Stott SL, Smas ME, Ting DT, Isakoff SJ, Ciciliano JC, Wells MN, Shah AM, et al: Circulating breast tumor cells exhibit dynamic changes in epithelial and mesenchymal composition. Science 339: 580-584, 2013.

54. Yu H, Ni YN, Liang ZA, Liang BM and Wang Y: The effect of aspirin in preventing the acute respiratory distress syndrome/acute lung injury: A meta-analysis. Am J Emerg Med 36: 1486-1491, 2018.

55. Boyle AJ, Di Gangi S, Hamid UI, Mottram LJ, McNamee L, White G, Cross LJ, McNamee JJ, O'Kane CM and McAuley DF: Aspirin therapy in patients with acute respiratory distress syndrome (ARDS) is associated with reduced intensive care unit mortality: A prospective analysis. Crit Care 19: 109, 2015.

56. Rothwell PM, Wilson M, Price JF, Belch JF, Meade TW and Mehta Z: Effect of daily aspirin on risk of cancer metastasis: A study of incident cancers during randomised controlled trials. Lancet 379: 1591-1601, 2012.

57. Liao X, Lochhead P, Nishihara R, Morikawa T, Kuchiba A, Yamauchi M, Imamura Y, Qian ZR, Baba Y, Shima K, et al: Aspirin use, tumor PIK3CA mutation, and colorectal-cancer survival. N Engl J Med 367: 1596-1606, 2012

58. Sahasrabuddhe VV, Gunja MZ, Graubard BI, Trabert B, Schwartz LM, Park Y, Hollenbeck AR, Freedman ND and McGlynn KA: Nonsteroidal anti-inflammatory drug use, chronic liver disease, and hepatocellular carcinoma. J Natl Cancer Inst 104: 1808-1814, 2012

59. Takada S, Miyashita T, Yamamoto Y, Kanou S, Munesue S, Ohbatake Y, Nakanuma S, Okamoto K, Sakai S, Kinoshita J, et al: Soluble thrombomodulin attenuates endothelial cell damage in hepatic sinusoidal obstruction syndrome. In Vivo 32: 1409-1417, 2018. 